\title{
Influence of Change of Environmental Management Thought on the Environmental Protection Industry
}

\author{
Mo-Li Qu, Jie Xing, Qiang Wang \\ Heilongjiang Provincial Research Academy of Environmental Sciences, Harbin, China \\ E-mail: 13039962345@126.com, 18686885851@163.com, jackeywang@163.com
}

\begin{abstract}
In the situation of the new normal during the "13th Five-Year" period, reform of environmental management mode have been put forward series of new challenges on the scale of environmental protection industry and the ability of the demands. In this paper, the connotation and development history of the environment management were introduced. Based on that, for the environmental protection industry with policy driven characteristics, the change of environmental management thought has profound influence on their development.
\end{abstract}

Keywords-Environmental Management; Environmental Protection Industry; Influence

\section{INTRODUCTION}

With the rapid development of the world economy, the contradiction between environmental resources, environmental capacity and economic and social development needs has become increasingly prominent. However, due to historical factors, China's modernization is later than the western developed countries for decades. When the western developed countries have been out of the plight "first pollution, after the governance", and began to pursue a more stringent environmental management model and standards, China is still seeking a balance between the economic, social development and environmental needs. The environmental management, as a means of plan, organization, coordination, control and supervision to achieve the desired environmental goals, can be helpful to prevent and solve the environmental problems [1]. It plays a pivotal role in environmental protection. With the Chinese economy into the "new normal" stage, the government vigorously promote the structural reform of supply side. Major changes have been taken place in environmental management idea in China, namely from reducing pollutant emission to improving the environmental quality. The pollution reduction effect must be verified by the quality of the environment. New changes and new requirements of the national environmental management ideas will inevitably bring new opportunities for the development of environmental protection industry. In this paper, the development of environmental management ideas was introduced in detail. Under the new ideas, reference for the direction of the development of environmental protection industry was provided.

\section{CONNOTATION OF THE ENVIRONMENT MANAGEMENT}

Environmental management is a branch of modern management science, and is a cross subject between environmental science and modern management science [2]. Its emergence and development has experienced a long process. The concept of environmental management was produced in the practice of human beings in the fight against environmental pollution.

From the beginning of the 50's, people became more and more aware of the importance of the environment, and environmental management was sprouted and continued to develop and improve. After 80 years, environmental management had become a complete discipline. In China, from the first national environmental protection conference in 1973 to 1981 , environmental management was to organize pollution control as the center. Environmental management was understood as various effective measures and means to control the pollution behavior using by environmental protection departments in a narrow sense. In this narrow understanding, the environmental protection department is the main body of environmental management, and the source of pollution as the object. It didn't think highly of the national economic and social development strategy, without taking into the management of people. Therefore, the narrow sense of environmental management can't fundamentally solve the environmental problems.

By 1990s, with the development of environmental problems and the improvement of people's awareness on environmental issues, it was generally recognized that, in order to fundamentally solve the environmental problems, we must stand in the strategic height of economic and social development to take measures, from the comprehensive decision of regional development to solve environmental problems. With the transformation of this thought, the scope of environmental management was extended, and the connotation of environmental management was deepened. Generalized environmental management refers to starting from the "human - environment" system, promoting the coordinated development of economic construction, urban and rural construction and environmental protection through overall planning, rational layout. This will not only develop the economy to meet the basic needs of human beings, but also not beyond the limits of the environment. The specific connotation of this concept includes: (1) Environmental management is a kind of management activity aiming at the secondary environment problem, mainly to solve the 
environmental problems caused by human activities. (2) The core of environmental management is the management of people. Human is the main body of all kinds of behavior, and it is the source of all kinds of environmental problems. The change of environmental management object is an important symbol of theoretical innovation and practice deepen of environmental management. (3) Environmental management involved in all fields of society, economy and resources. It is closely related with other management work in the country, and is an important part of the national management system. Therefore, the national development strategy determines the environmental strategy, and the environmental management system and mode depends on the state management system and mode. The construction of environmental management system was still in the embryonic stage [3].

\section{DEVELOPMENT HISTORY OF ENVIRONMENTAL MANAGEMENT}

The development of environmental management in China has experienced four stages. The first stage is start-up phase of environmental management system (1971 1979) [4]. In this stage, environmental law had not yet been tried. A highly centralized planned economic system was implemented, and heavy industry is preferred, which eventually lead to serious ecological damage and high energy consumption, high pollution, industrial pollution problems. The government gradually began to pay attention to the environmental problems, but under the planned economy system, economic construction was the focus. Environmental management had not been paid enough attention, and the construction of environmental management system was still in the embryonic stage. Generally speaking, the environmental management was lack of legal basis in this stage. Influenced by planning system, environmental management institutions were not independent, and their environmental management functions were very limited.

The second stage is the development stage of the environmental management system (1979 1989) [4]. The third plenary session of the eleventh central committee clearly put forward tasks of economic system reform and political system reform. National construction entered a new period of development, and multiple economic forms began to emerge. National economic and political development and construction were groping forward, and environmental management system was also in constant development. A large number of environmental laws and regulations promulgated. In 1979, "environmental protection law in trial" was promulgated, which specified the central and local authorities to set up environmental protection administrative institutions and their responsibilities. In 1982, "constitution" clearly stated that the state had the function of protecting and improving the living environment and ecological environment. The second national environmental protection conference was held in 1983, which made it clear that environmental protection was a basic state policy. Since then the importance of environmental protection had been raised to a new level. Environmental management institutions became independent, and their functions were gradually clear. Environmental management was mainly to control pollution as the center in this stage. The task of the management department was to plan, arrange, organize, implement, check and supervise. Environmental management ideas were from simple pollution control to "prevention first, prevention and control of combination". However, the means of environmental management was still relatively single.

The third stage is the formation stage of the environmental management system (1989 2015) [4]. During this period, great changes had been made in the national economy and politics. "Environmental protection law" was promulgated by revised in 1989. The system of supervision and management of environmental protection was clearly stipulated in the form of comprehensive environmental protection basic law for the first time. The socialist market economy system was established after 1992, and the strategy of sustainable development began to implement. The coordination and sustainable development of environment and economy was emphasized. Scientific Outlook was proposed in 2003, which lay the ideological foundation for the coordinated development of environment and economy in a higher level and wider field. The concept of ecological civilization was clearly put forward, which required speeding up the transformation from the way of economic growth to the economic development mode. In this stage, the legal system of environmental protection had been perfected continuously, and environmental management agencies and their function were upgraded. Environmental management extended from simple pollution control to the protection of natural resources and the management of environmental factors. Pollution control idear was changed from the "end of control" to "source control" and "the whole process of control". Pollution control method wrer from point source control to combination of point source and surface source control, and pollution control pattern changed from city to city and countryside. In the past, the environmental management methods were mainly controlled by the government. But in this stage, combined with the market rules, the government played a guiding role.

The fourth Change of environmental management ideas was from 2015. From this year, China's economic growth rate slowed, and the economic development came into the "new normal". At the same time, the new environmental protection law was promulgated and implemented. With the published of water, air and soil pollution prevention action plan, environmental protection was mentioned in an unprecedented height. Environmental management ideas changed from the total amount of pollutants control to the improvement of environmental quality. Work focus changed from controling increment priority to cuting stock first. Management path changed from the past environmental capacity to the current environmental flow[5]. In this stage, the structural reform of the supply side was vigorously advocated. Speed up the construction of ecological civilization and promote the development of green industry. Marketization mechanism was carried out. The environmental protection industry as the "emerging industries" in 13th Five-Year, was planned into the pillar industry of the national economy. 


\section{INFLUENCE OF ENVIRONMENTAL MANAGEMENT REFORM}

For the environmental protection industry with policy driven characteristics, the change of environmental management thought has profound influence on their development. Since the implementation of the new environmental law, enforcement was stepped up. Under the condition of market economy, the government's strict law enforcement will inevitably create a huge market demand in the field of governance. Solutions to the traditional pollution reduction not only need to be provided, solutions to environmental quality improvement but also need to be provided. In order to improve the effective supply of public environmental services, government changed in environmental management ideas. The construction of ecological civilization was carried out in an all-round way. By opening market, perfecting cooperation mode, promoting the third party governance, and introducing PPP model, the development of environmental protection industry was effectively promoted. Mass concentration of pollution control has become the new normal; the overall size of the environmental protection industry will be further expanded. Government purchase of environmental services has become the new norm, the transformation and upgrading of environmental protection industry will further accelerate. Diversification of investment and financing of environmental protection has become the new normal; the market will further stimulate the environmental protection industry [6]. Promote the improvement of resource products pricing, and bring the environmental costs into production costs in full gradually. At the same time, strengthen the green regulation of financial capital market, and promote the construction of green supply chain. The essence of the environmental economic policy is to solve the environmental pollution problem by the way of developing the environmental protection industry.

\section{SUMMARY}

After more than 40 years of development, environmental management policies, regulations and standards have been formed system in China. Environmental management at all levels must change ideas, and play the role of market guidance, supervision. Under the market mechanism, the business scope and development mode of China's environmental protection industry are constantly extending and changing through the continuous innovation and promotion of the industrial model. The development of environmental protection industry should speed up the adjustment of industrial structure, grasp the development opportunities brought by favorable policies, achieve leapfrog development, and provide strong support and protection for the construction of ecological civilization.

\section{ACKNOWLEDGMENT}

This research was financially supported by the project" Ability Construction of Environmental Pollution Damage Assessment in Heilongjiang Province”.

\section{REFERENCES}

[1] Y. Ma, Z. F. Dong, H. X. Li, "Thoughts and focus on the reform of environmental management system in China", World environment, vol.2, pp. 16-18, 2016.

[2] P. H. Yin, "Review and Reflection on the reform of environmental management system in China", Environment and sustainable development, vol.2, p.003, 2016.

[3] Y. Yang, X. R. Cheng, "Opinion on the change of the concept of environmental management in China", Scientific consultation, vol.1, pp.40-41, 2016.

[4] Y. Tie, "A study on the reform of China's environmental administration system", Ph.D. dissertation, Wuhan University, 2010, pp.27-39.

[5] W.S. Chai, Y Wang, B.J. Li, "The influence of environmental management strategic transformation on the development of environmental protection industry", China Environmental Protection Industry, vol.4 , pp.13-16, 2016.

[6] Information on http://www.drc.gov.cn/xsyzcfx/20150424/4-42886939.htm. [Accessed:Apr. 24, 2015 ] 